\section{DIAGNOSTICS OF} \section{AUTOMATED TECHNOLOGICAL DEVICES} JOZEF PETERKA ${ }^{1}$, YURY RAFAILOVICH NIKITIN ${ }^{2}$, PAVOL BOŽEK ${ }^{1}$

${ }^{1}$ Slovak University of Technology in Bratislava, Faculty of Materials Science, Institute of Production Technologies, Slovak Republic, ${ }^{2}$ Kalashnikov Izhevsk State Technical University, Izhevsk, Russia

DOI: 10.17973/MMSJ.2020_10_2020051 jozef.peterka@stuba.sk

Automated technological devices need diagnostics. At present, it is possible and necessary to use a wide range of sensors, computing systems and artificial intelligence methods based on neural networks, fuzzy inference systems in diagnostic systems. This paper proposes three models of information processes for diagnosing mechatronic systems - parallel, sequential and combined. To diagnose the nodes of mechatronic systems showed that it is necessary to combine neural networks and fuzzy logic. For a fuzzy inference system, it is proposed to use such parameters as the value of the diagnostic parameter, the trend of this parameter, and the value of the node operating time. Examples of diagnostics of such units of mechatronic systems as bearings and electric drives based on a neural network and fuzzy logic are given. Experiments have been carried out confirming the correctness of the reliability of the diagnostic model.

KEYWORDS

diagnostic, technological devices, mechatronic systems, neural network, Computer Numerical Control, Artificial Intelligence

\section{INTRODUCTION}

Brushless direct current (BLDC) motors belong to the type of electric motors, which is gaining popularity fast, thanks to its great performance and the progress of the microprocessor control development. The presented paper discusses the new PWM (Pulse-width modulation) switching strategy, which is based on sensor control of the rotor position. This strategy ensures that the torque ripple in BLDC motor is minimized [Abramov 2015]. The methodology for tuning the parameters in BLDC motor drive system and diagnosis for the BLDC motor faults detection including the wavelets and state estimation are described in [Abramov 2014a]. Stator winding faults and bearing faults, that cause most of the motor failures, are examined [Abramov 2014b].

A new method, presented in [Basseville 1993], is oriented on the parameters, which are operated under constant movement. The usage of quadratic time-frequency representations provided an identification in motors that operate in the terms (conditions) the continually changing [Cowan 2013].

Three algorithms are presented for the identification of the faults of the BLDC motors are presented three algorithms. These algorithms are able to trace and discover rotor faults in transient or non-stationary current signals [Zhang 2010, Frank 1990, Hammer 2010].

In papers [Aldrich 2013, IME 2012, Isermann 2006, Lee 2007, Luo 2017] is presented the union of diagnostic systems and control systems too. From the view of economic, thanks of increased reliability are the efficiency of the diagnostics systems higher, reduced number of rejections, accidents reduction, decrease of downtime of expensive equipment, increase of the service life and reduction of repair and maintenance costs.

\section{MODELS OF INFORMATION PROCESSES FOR DIAGNOSTICS OF MECHATRONIC SYSTEMS}

The Mechatronic Object Diagnostic System is a set software and hardware components that consists of multiple sensors, analog-to-digital converters, a computing device that processes information and operates based on the technical condition [Nikitin 2010, Felkaoul 2017, Saitaev 2014]. Accordingly, information process models and hardware models for systems diagnosing mechatronic objects are considered [Stepanov 2014a, Stepanov 2014b, Stepanov 2013]. Analysis of existing diagnostic models of MS makes it possible to conclude that there are no formulas for models, information processing algorithms and decision making [Tiwari 2018, Toro 2018]. The diagnosis of automated technological devices, MS and their components are an urgent task [Trefilov 2019, Turygin 2018, Guan 2015]. Use of modern methods such as machine learning for state prediction [Peterkova 2017 \& 2018]

There are several information processes in the diagnostic system. The first information process determines how the diagnosis is organized. Determines the intervals, sequence of diagnostic modules, nodes, and MS elements. The second information process is used to decide on the technical condition of modules, nodes and MS elements based on Al methods.

\section{Information process models, for determining the method of} diagnostics

Three models of MS diagnostic methods are proposed: parallel, sequential and combined.

1. Model of parallel MS diagnostics. All nodes and MS elements are diagnosed simultaneously. The technical condition monitoring is continuous. This method requires maximum cost - each node and feature has its own diagnostic microsystem. A parallel way of organizing the diagnostic process is recommended when there is a threat to human health and life. High reliability is required because there are nodes and elements with high rates of deterioration processes.

2. Model of sequential MS diagnostics. All nodes and MS elements are diagnosed, one by one. Regular monitoring of the technical condition is implemented. Nodes and elements have integrated sensors to measure diagnostic parameters. There is one regulator for information processing that processes information at certain diagnostic intervals. This method requires minimal costs. However, it is necessary to calculate the intervals of diagnosis of nodes, elements and to determine the sequence of their diagnosis.

3. Model of combined MS diagnostics. the most critical nodes and elements of the MS are diagnosed simultaneously and the rest - at certain intervals of diagnosis. The criterion of minimum economic losses during MS operation must be used as a target function in the selection of the method of organizing the diagnostic process. Economic losses consist of equipment downtime, STOP in product manufacturing, and diagnostic system costs.

Model of information process on technical state of mechatronic systems

In order to properly decide on the technical state of MS, it is necessary to analyse the information provided by sensors. The following diagnostic parameters are used: electrical current, 
voltage, power and temperature fields, vibroacoustic parameters, spatial position accuracy, firmness, performance parameters, time periods (intervals). Diagnostic parameters have distinct physical characteristics; therefore, only mathematical apparatus is needed for their analysis. Neural networks, fuzzy logic, and genetical algorithm are suitable as such devices.

The NN that consists of modules corresponding to each MS node can be used to diagnose MS. These modules process the information based on the parameters obtained from the diagnostics. We know these NN layers [Stepanov 2014]:

- input layer,

- hidden layer, in which are the received data processed, the scales are assigned in the learning process [Turygin 2018, Enguang 2015],

- output layer.

Each input layer module contains a precise number of neurons. The number of neurons of the preceding layer is the same as the number of neurons of the hidden layer [Stepanov 2014]. Every module that has its own input layer has no reference to other modules. Each module is necessarily connected to the output layer separately. The output data is a matrix whose rows correspond to the state of a diagnosed node and the columns correspond to defects in that node.

So far, Anti-friction bearings in MS with integrated microprocessors have been developed and used, which measure the angular position and the rotational speed. It is possible to create electric propulsion that, in addition to MS, will have integrated the diagnostic system for detecting a defect of windings, rotor, mechanical gears, powerful semiconducting devices.

The main methods used for fault detection of an electrical drive in MS are: vibration diagnostics, analysis of motor's actual electrical current, measurement of electromagnetic field of motor with measuring coils, chemical analysis, temperature, torque and power measurement, infrared measurement, acoustic noise measurement, radiofrequency measurement, measurement of partial discharges. The most common methods of these are vibration diagnostics, analysis of the motor's actual electrical current and temperature analysis due to simplicity, high accuracy, and reliability. In many cases, the vibration methods are effective in detecting defects of electrical engines. However, vibration sensors, such as accelerometers, are installed on expensive devices where the cost of continuous condition monitoring is justified.

The NN with the reverse error propagation algorithm is used for diagnostics of MS. Errors in robots, manipulators, machining centres and CNC (Computer Numerical Control) machines [Pokorny 2012], AC (Automation Cell) [Calvo 2014], located in the following subsystems, are considered as an example of errors in MS. The mechanical subsystem's defects are listed as:

- robots, mobile manipulators,

- regals, columns, sliding tables,

- universal spindle units, crankshafts, and driveshafts,

- gearboxes, starter couplings, brake coupling,

- cooling systems, lubricants.

Defects of electrical and electromechanical subsystems are specified in the following list:

- propulsion engines, generators,

- electrical cabinets with electrical equipment,

- other elements of the subsystems.

Hydraulic (tire) defects are mentioned as follows:

- $\quad$ hydraulic (pneumatic) cylinders, hydraulic engines,

- hydraulic pumps,

- control devices.

Defects of CNC technological equipment and tools
To measure diagnostic parameters force sensors are used to diagnose instrument, temperature sensors, current and voltage sensors for electric motors, sensors, and vibration sensors. Figure 1 shows a block diagram of a hybrid intelligent diagnostic system that represents a software and hardware complex. The knowledge database (rules) contains a set of rules "If ... then ... ". The decision subsystem uses the knowledge database to process the information, the database contains.

The decision subsystem provides the interface with the operator and operation in real-time. The hybrid intelligent diagnostic system software is based on algorithms for processing the information and deciding on the state/status of MS elements and nodes. Algorithms are based on intelligent data analysis algorithms. Such algorithms, called Data mining [Zidek 2016, Nemeth 2017, Nemeth 2019], enable the determination of the technical state and predict its change by the following tasks:

- The simulation of complex non-linear variations between I\&O data,

- The identification of trends,

- Operating with loud signals and incomplete data,

- The actualization of the model, when new data becomes available,

- The identification of abnormal data.

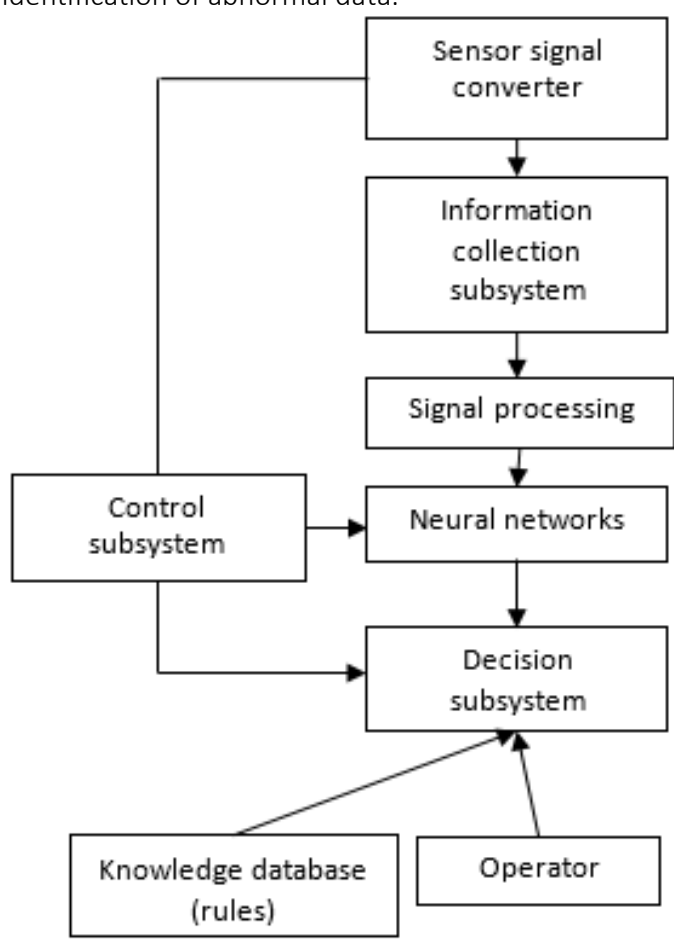

Figure 1. Block diagram of a hybrid intelligent diagnostic system

To solve the problems of intelligent diagnostics, it is necessary to integrate NN with fuzzy logic [Rezoug 2012, Janglova 2004, Mohd 2013]. For example, in the diagnosis of the machine spindle unit, axial and radial loads and speeds have a large impact on vibration and noise. Under the influence of load, the bearing clearance/voltage, the stiffness and the temperature in the bearings increases. The bearings clearance/voltage and the thermal deformation of the spindle is affected by the temperature change.

Therefore, four parameters: axial and radial load, temperature and rotation speed affecting the rules of using $N N-x_{1}, x_{2}, x_{3}, x_{4}$. Each rule uses its NN. Generally, we can write: "If $X=\left\{x_{1}, x_{2}, x_{3}\right.$, $\left.x_{4}\right\}$ is $A_{s}$, then $y_{s}$ is output belonging to the NN $S$, where $A_{s}$ is a fuzzy set of the conditional part of each rule. Each NN $S$ has $n$ inputs for diagnostic parameters and own scales. Figure 2 shows a model of a NN of fuzzy inference. 


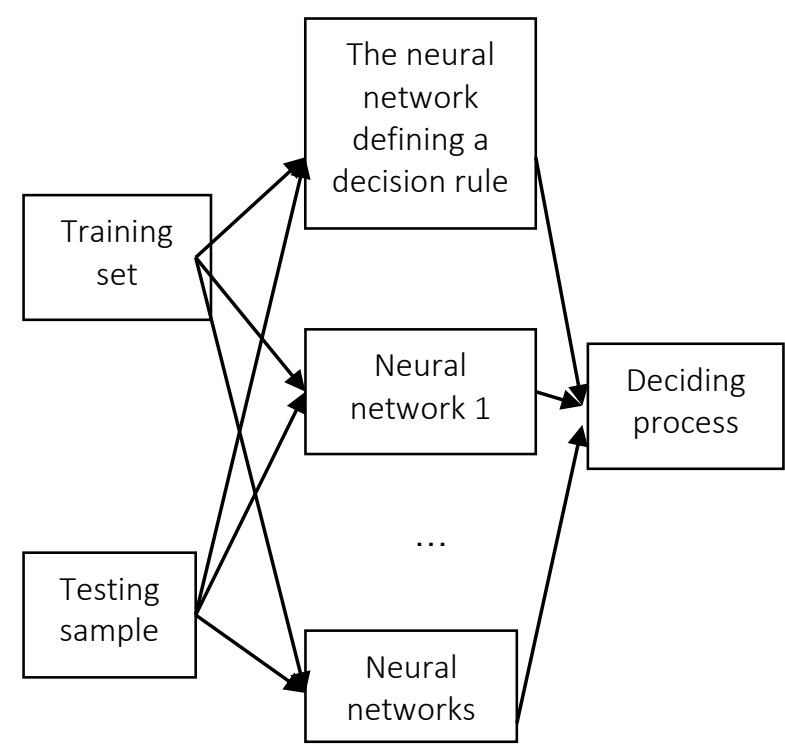

Figure 2. Model of a neural network of fuzzy inference

The NN model of fuzzy inference is crucial for propose of following algorithm for deciding on the technical state of MS:

Step 1. The creation of training and test samples. The training sample is created on a database acquired in different modes of MS operation.

Step 2. Cluster the training file. The training file is divided into $r$ classes.

The $\mathrm{N}$-dimensional entrance space is divided into $r$ subspace. A decisive rule is set for each subspace.

Step 3. Training of the NN defining the decision rule. For each input vector $X_{i} \in R_{s}$ there is a subspace for decision rule $M_{i} . R_{s}$ is a subspace for decision rule. After training and testing, the NN is able to determine the level to which each input vector and to which class of subspace Rs belongs. In this algorithm, it is possible to modify membership functions as a result of obtaining new data from experts to obtain more reliable results. Step 4. NN $S$ learning. The training set with input vector $X_{i} \in R_{S}$ and output value $y_{s}$ is fed to NN $S$, a model of NN.

Step 5. Decision making.

The Gaussian function is selected as the term of membership functions of the linguistic variable $M$. The Gaussian function is quite simple, differentiable and defined only by two parameters. These reasons reduce the computing complexity of the algorithm. Linguistic variables $z, s$ functions are chosen for the functions of expressions $L, H$.

There was chosen Mamdani fuzzy inference (MFPID), because of its good parameter settings. In the Figure 3 we show the example of terms $L, M, H$ functions of $I \& O$ variables.

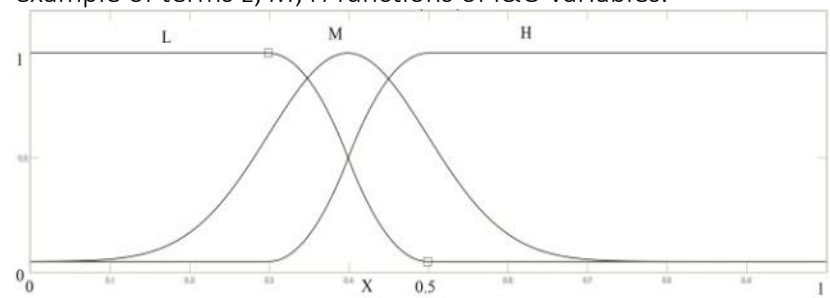

Figure 3. The example of terms L, M, H functions

When three linguistic variables are used with three terms combined with two logical operations AND, OR, 7 rules are possible. The mentioned rules, as shown below, reflect the dependence of the technical condition on the quantity of parameters, adequately the development of the resource too:
If ( $x$ is $L)$ and ( $d$ is $L)$ and ( $t$ is $L$ ) then ( $z$ is $L$ )

If ( $x$ is $M)$ and ( $d$ is $L)$ and ( $t$ is $L)$ then ( $z$ is $M$ )

If ( $x$ is $L)$ and ( $d$ is $M$ ) and ( $t$ is $L)$ then ( $z$ is $M$ )

If ( $x$ is $L)$ and ( $d$ is $L$ ) and ( $t$ is $M$ ) then ( $z$ is $M$ )

If $(x$ is $H)$ then ( $z$ is $H)$

If $(d$ is $H)$ then $(z$ is $H)$

For a given input vector using NN $S$, the output value is calculated.

Thus, using the presented algorithm, which uses a fuzzy inference NN model, the technical state of MS elements and nodes is determined.

Sensor signals inform about the modes of operation of the MS. At present, there are no rules for network selection. Rosenblatt's perceptron network is suitable because it has an error propagation algorithm and allows us to minimize multilayer perceptron error. To select type of neurons, it is necessary to estimate the time to calculate the threshold activation function and the ability to differentiate this function. At each iteration of the backbone network, scales of the NN are modified to improve the solution of one example.

For a given input vector using NN $S$, the output value is calculated. Thus, using the presented algorithm, which uses a fuzzy inference NN model, the technical state of MS elements and nodes is determined. There are currently no network selection rules and types of neurons.

Rosenblatt's perceptron network is suitable because it has a back-propagation algorithm to minimize multilayer perceptron error.

In order to use the reverse error propagation method, the transmission function of neurons must be differentiable. Therefore, exponential sigmoidity is selected as the activation function. It is necessary to select the number of neurons and layers. If there are too few neurons or layers in the network, the network will not be able to learn, and the error will remain large during network operation. If there are too many neurons or layers, the network speed will be low, will needed a lot of memory and the network will be retrained. This means that the output vector will transmit insignificant and irrelevant details on the output e.g. will not be able to learn. Scaling is used to prepare the input and output data to bring the data to an acceptable extent. There is no general rule on how many hidden layers should be. Usually, there are 1-3 hidden layers. The more nonlinear problems, the more hidden layers should be. Using NN, the known stages of problem-solving of MS are emphasized:

- Data preparation and normalization,

- Choice of network topology,

- Experimental selection of network characteristics,

- Experimental selection of learning parameters,

- Proper network training,

- Checking the adequacy of training,

- Parameter settings,

- Final training,

- Publishing the network for future use.

\section{NEURAL NETWORK FOR ANTI-FRICTION BEARNINGS DIAGNOSTICS}

As an example, the development of a NN for bearing assemblies diagnostics that are common nodes in MS. The Rosenblatt perceptron network with Widrow-Hoff teaching algorithm was chosen for the diagnostics of MS bearing assemblies. This network allows minimizing multilayer perceptron error. 
Four layers were chosen for the bearing assemblies' diagnosis experiment: one input, two hidden layers for the weight attribution and calculation of the output parameters taking into account weights, one output. Then, after learning the network, three layers will be used:

1. Input,

2. Hidden layer,

3. Output.

Informative parameters of the bearing unit are input - it is the frequency and amplitude of vibrations determined by spectrum. The error frequency of bearing assemblies' various elements was given by known terms. The input parameter can be the temperature of bearing circles/rings, but the temperature can be increased by relatively serious errors. In the case of initial errors, the temperature of bearing assemblies does not increase, therefore it is not considered as a diagnostic feature in this example. The Rosenblatt perceptron Network is a normal perceptron having a training sample consisting of input vectors, each having its own target vector. Components of input vector are represented as the continuous scope of values; the target vector components are binary values ( 0 or 1 ). After training, at the input, the network receives a set of continuous inputs and generates the required output as a vector with binary components. As is widely known, a defect in various states does not need to be a unique value but is within a range that requires a continuous field of output target values. The maximum frequency of the vibration acceleration signal for single row radial ball bearing 6-180605 with double seals is $850.9 \mathrm{~Hz}$. Table 1 shows the frequency of manifestations of various bearing defects.

Table 1. Manifestation frequency of various bearings defects/frequency of manifestation of various bearing defects

\begin{tabular}{|c|c|c|}
\hline $\begin{array}{c}\text { Indication of } \\
\text { frequencies at } \\
\text { which bearing } \\
\text { defects occur }\end{array}$ & $\begin{array}{c}\text { Frequency of rotation } \\
\text { of bearing parts }\end{array}$ & $\begin{array}{c}\text { Frequency of } \\
\text { manifestation } \\
\text { of various } \\
\text { bearing } \\
\text { defects, (Hz) }\end{array}$ \\
\hline $\mathrm{f}_{\mathrm{kl}}$ & $\begin{array}{c}\text { Frequency of bearing } \\
\text { cage rotation }\end{array}$ & 98.18 \\
\hline $\mathrm{f}_{\mathrm{vt}}$ - vok & $\begin{array}{c}\text { Frequency of anti- } \\
\text { friction element rolling } \\
\text { on the outer ring }\end{array}$ & 589.09 \\
\hline $\mathrm{f}_{\mathrm{vt}}-\mathrm{vnk}$ & $\begin{array}{c}\text { Frequency of anti- } \\
\text { friction element rolling } \\
\text { on the inner ring }\end{array}$ & 850.90 \\
\hline $\mathrm{f}_{\mathrm{vt}}$ & $\begin{array}{c}\text { Frequency of anti- } \\
\text { friction element rotation }\end{array}$ & 638.18 \\
\hline
\end{tabular}

For experiments, the MMA6233Q sensor with a frequency range of up to $900 \mathrm{~Hz}$ was chosen. It has a built-in amplifier, low-pass filter with high sensitivity and a wide range of accelerations. During the experiments, the PCS500 digital oscilloscope was used to acquire an online frequency spectrum. The sensitivity of the MMA62330 sensor is $120 \mathrm{mV} / \mathrm{g}$. On the PCS500, the 1-volt digital oscilloscope display corresponds to a vibration acceleration of $8.33 \mathrm{~g}$. The DREMEL 300 electric drive was used as the motor for turning the inner ring of the bearing. Figure 4 shows a photograph of an experimental test bench consisting of an electric drive (1), a bearing (2), a vibration acceleration sensor (3), a digital oscilloscope (4), a personal computer (5).

Figure 5 shows the error-free carrier signal spectrum 6-180605 - of rotational speed error at $11250 \mathrm{~min}-1$. We can see that there are clear peaks at 100 and $200 \mathrm{~Hz}$. These frequencies are harmonics of the industrial frequency of $50 \mathrm{~Hz}$ and are caused by interference from the $50 \mathrm{~Hz}$ network.

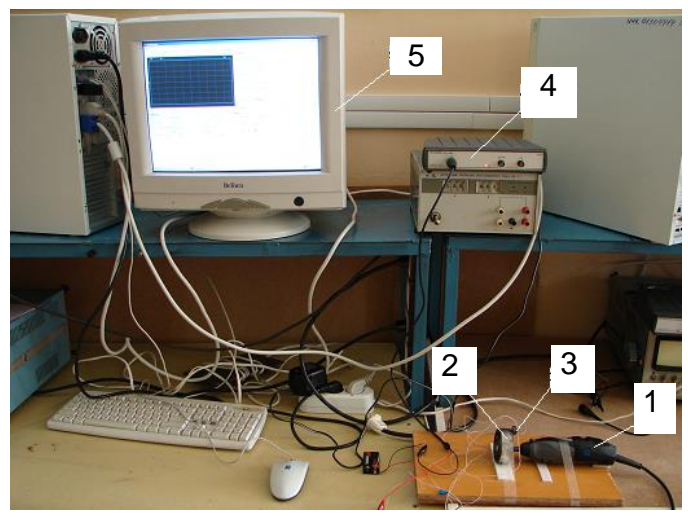

Figure 4. Experimental stand

1 - electric drive, 2 - bearing, 3 - vibration acceleration sensor, 4 digital oscilloscope, 5 - personal computer

There are also peaks at a frequency of $75 \mathrm{~Hz}$ and a second harmonic frequency of $150 \mathrm{~Hz}$. Other apparent vibration peaks are not observed, the average vibration level is negligible at 0.5 $V$, indicating good bearing condition.

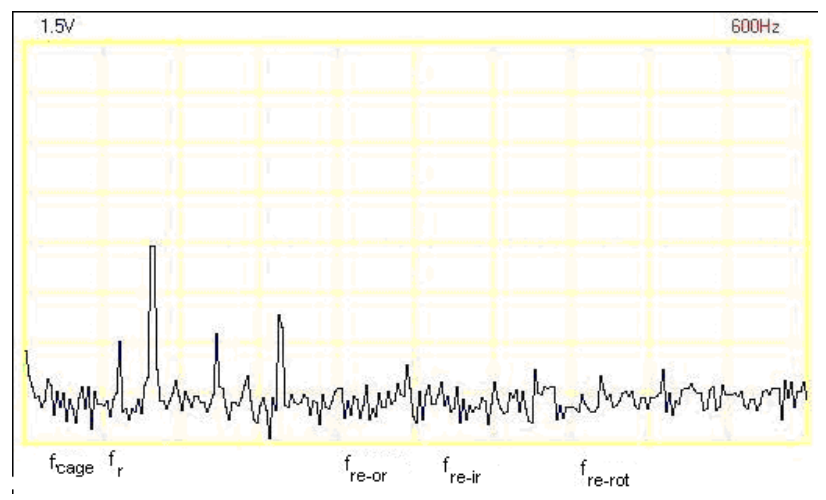

Figure 5. The error-free carrier signal spectrum 6-180605 at 11250 rpm

Figure 6 demonstrates the signal spectrum of the same bearing with artificial damage in form of transverse grooves on the outer ring. Defects of this type are reflected in the spectrum as peaks in the high-frequency field. By comparing the defected bearing with the defect-free bearing, it was discovered that the spectrum of the defected bearing increases overall vibration level by $0.7 \ldots 0.8 \mathrm{~V}$ and there are wide peaks at $250 \mathrm{~Hz}$, which agrees to rolling frequency of anti-friction elements on the outer ring and at $340 \mathrm{~Hz}$, which agrees to rolling frequency of anti-friction elements on the inner ring.

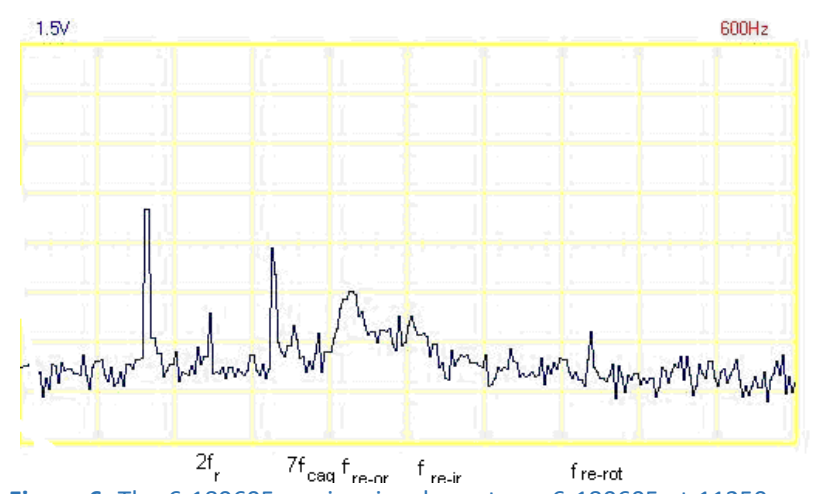

Figure 6. The 6-180605 carrier signal spectrum 6-180605 at 11250 rpm with defect

Figure 7 illustrates the spectrum of bearings for defect 6 180605 with an increased radial load. In this graph, the amplitudes of the spectral components increased at frequencies that are multiples of $50 \mathrm{~Hz}$, at a separator rotation frequency of $0.78 \ldots 0.8 \mathrm{~V}$ at the rotor frequency and at its second harmonic frequency. 


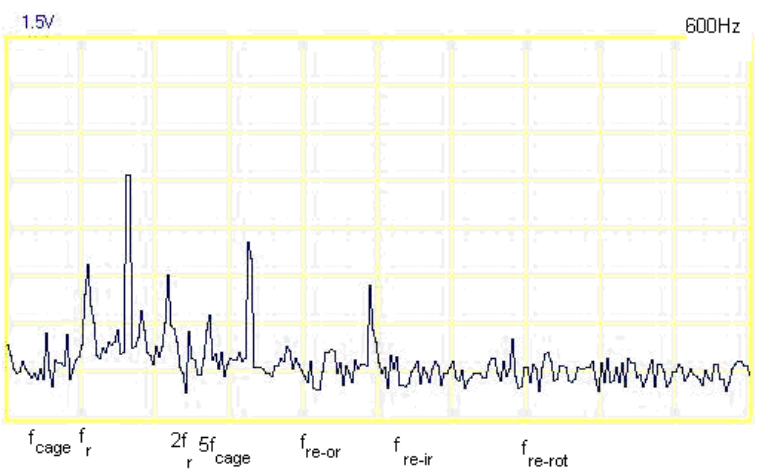

Figure 7. The carrier signal spectrum 6-180605 at $11250 \mathrm{rpm}$ under radial load

Figure 8 shows the signal spectrum of bearing 6206 at 7800 $\mathrm{rpm}$ without error. This spectrum also shows peaks at a frequency that is a multiple of $50 \mathrm{~Hz}, 100 \mathrm{~Hz}$, and $150 \mathrm{~Hz}$. The average vibration amplitude corresponds to a level of $3 \mathrm{~V}$.

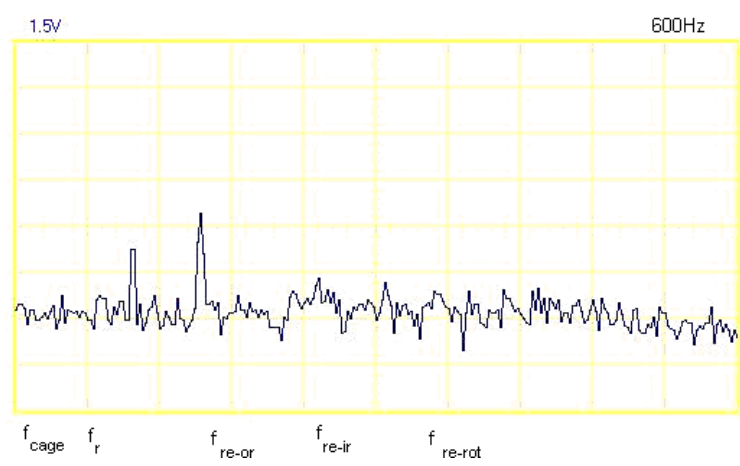

Figure 8. The carrier signal spectrum 6-180605 at a rotational speed of 180 rpm without error

The spectrum of the same bearing with a defect is demonstrated in Figure 9. The defect is damage to the outer ring in the form of transverse furrows. When comparing the defect-bearing spectrum with the defect-free bearing spectrum, an increase in vibration amplitude of $0.7 \ldots 0.8 \mathrm{~V}$ is observed at a frequency of $270 \mathrm{~Hz}$ of anti-friction element rolling frequency along the inner ring. The harmonic rotational frequencies of the bearing cage and outer ring will be recorded.

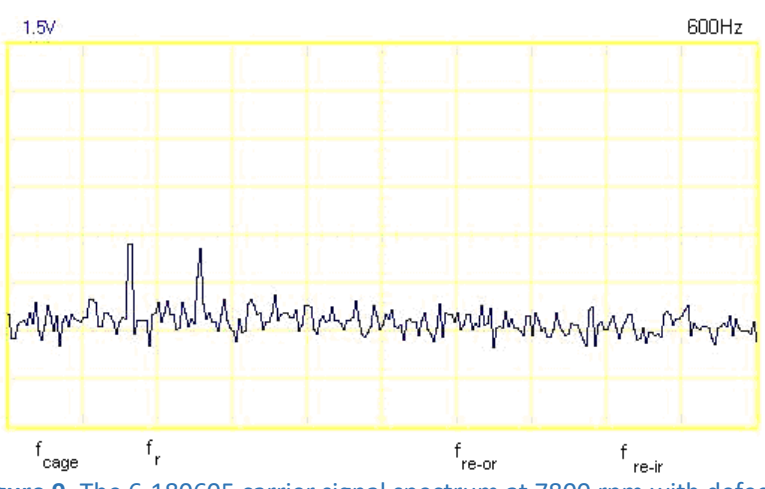

Figure 9. The 6-180605 carrier signal spectrum at $7800 \mathrm{rpm}$ with defect

The signal spectrum of bearing 6206 without defect at 14400 rpm is illustrated in Figure 9. This spectrum also shows peaks at a frequency that is a multiple of $50 \mathrm{~Hz}, 100 \mathrm{~Hz}$, and $150 \mathrm{~Hz}$. The average vibration amplitude corresponds to a level of $3 \mathrm{~V}$.

Figure 11 illustrates the spectrum of the same bearing as in Figure 9 but with defect. When comparing the defect-bearing spectrum with the defect-free bearing spectrum, an increase in the overall vibration level is observed at frequencies from 360 $\mathrm{Hz}$ to $0.7 \ldots 0.8 \mathrm{~V}$, with the maximum peak decreasing to the $510 \mathrm{~Hz}$, the rolling frequency of the outer ring anti-friction elements. The amplitude increased by $2 \ldots 2.5 \mathrm{~V}$.

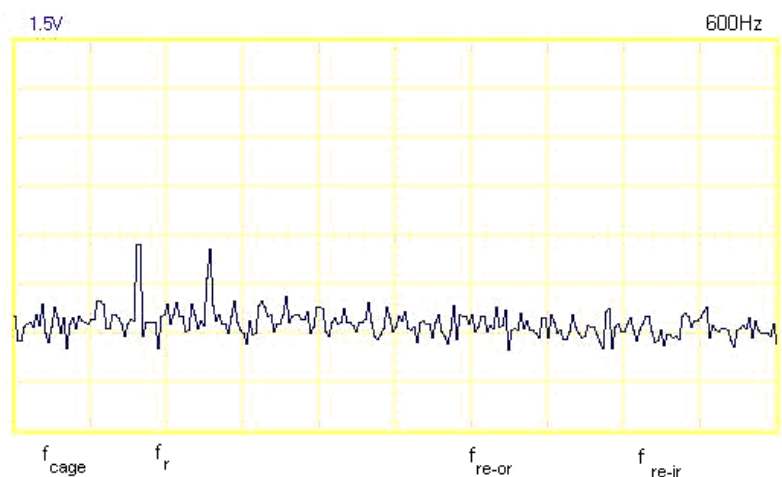

Figure 10. The carrier signal spectrum 6-180605 at $14400 \mathrm{rpm}$ without defect

When errors are present, the amplitude increases by an average of $0.75 V$ throughout the frequency spectrum, the vibration level increases by $1.5 \ldots 2 \quad 2$ at the rotational frequencies of the outer and inner ring anti-friction elements. While under the radial load the amplitude increases at rotor speed and at the industrial frequency of $50 \mathrm{~Hz}$ the peaks appear at the rotational speed of the separator.

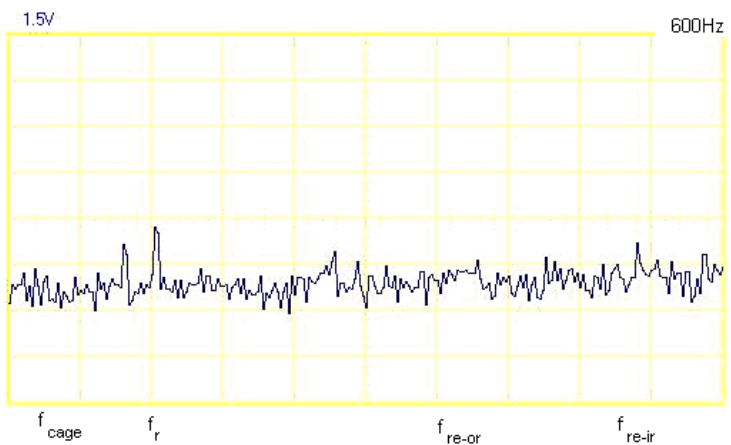

Figure 11. The carrier signal spectrum 6-180605 at 14400 rpm with defect

The NN modelling was performed in the MATLAB. The input data in all examples are presented in the form of a twodimensional vector, including frequency and corresponding amplitude:

- bearing cage rotation frequency,

- the bearing balls noise frequency on the outer ring,

- the bearing balls noise frequency on the inner ring,

- the rotational frequency of the anti-friction elements.

The NN input data of bearing 6-180605 are shown in table 2 . The target vector is a value that is the product of the logical addition of the binary values 0 and 1 , characterizing the absence of an error or its presence in the bearing components (bearing cage, outer ring, inner ring, anti-friction elements). Therefore, the expression OvOvOvO $=0$ means the absence of any defects and expression equal to 1 corresponds to the presence of a defect in the bearing.

Figure 12 demonstrates the training sample of NN in MATLAB for bearing 6-180605.

Table 2. The NN input data for the bearing 6-180605

\begin{tabular}{|c|c|c|c|}
\hline \multicolumn{4}{|c|}{ The neural network inputs } \\
\hline \multicolumn{2}{|c|}{ Frequency } & \multicolumn{2}{|c|}{ Amplitude } \\
\hline & & Defect-free & With defect \\
\hline$f_{l k}$ & 0.050 & 0.250 & 0.500 \\
\hline 5 & 0.250 & 0.210 & 0.470 \\
\hline$\pi$ & 0.375 & 0.246 & 0.530 \\
\hline$f_{l k-v o k}$ & 0.420 & 0.250 & 0.750 \\
\hline$f_{l k-v n k}$ & 0.550 & 0.250 & 0.500 \\
\hline$f_{v t}$ & 0.730 & 0.250 & 0.330 \\
\hline
\end{tabular}




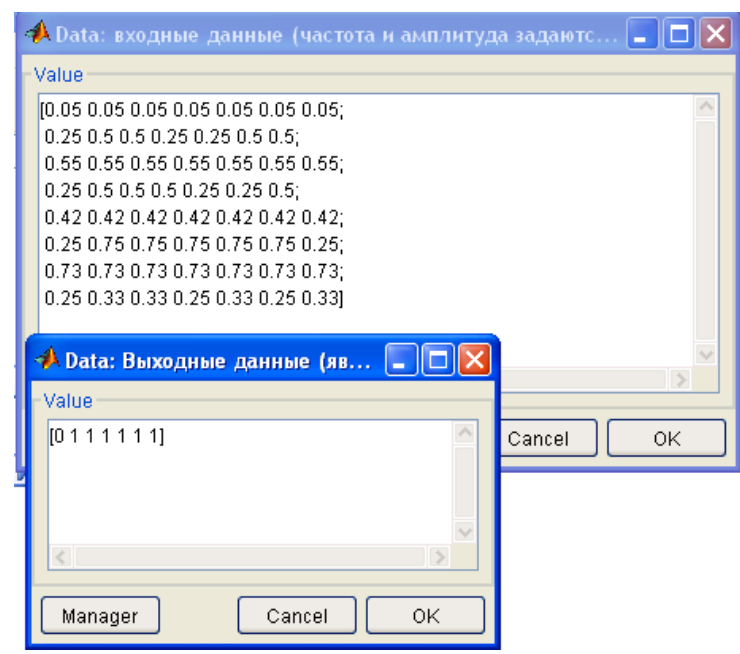

Figure 12. Training NN sample of the bearing 6-180605, output data

Figures 13 to 16 demonstrate the training and testing of the $\mathrm{NN}$. The target vector is a value that is the product of the logical addition of the binary values 0 and 1 that characterize the absence of the error or its presence in the supporting structural elements.

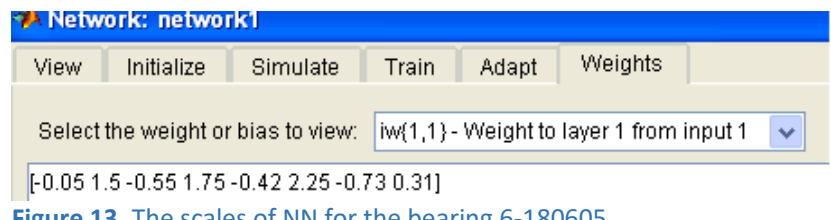

Figure 13. The scales of NN for the bearing 6-180605

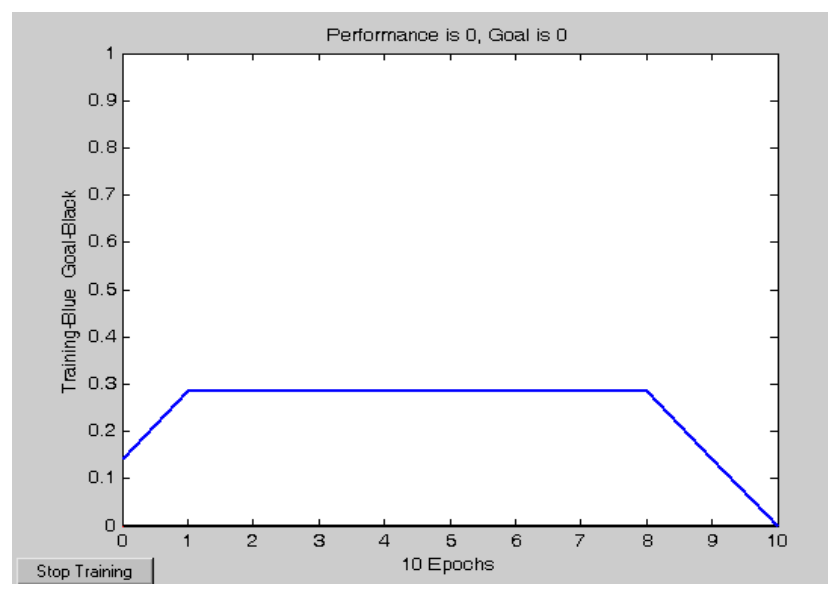

Figure 14. Neural network learning curve for the bearing 6-180605

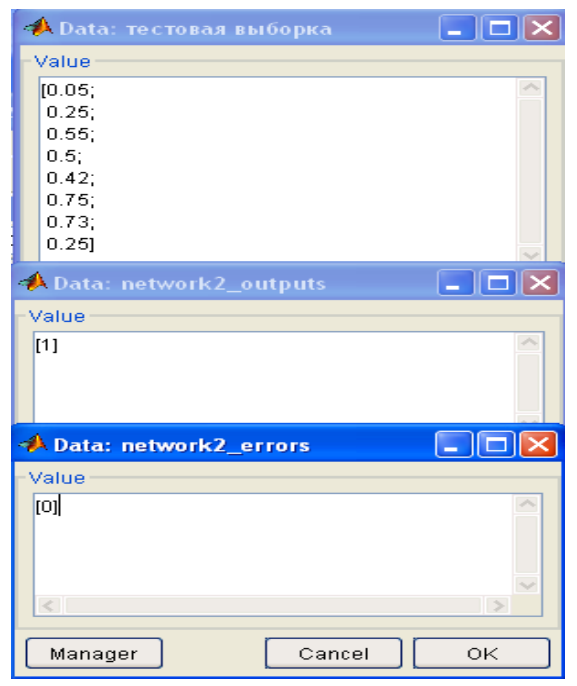

Figure 15. Neural network results for the bearing 6-180605

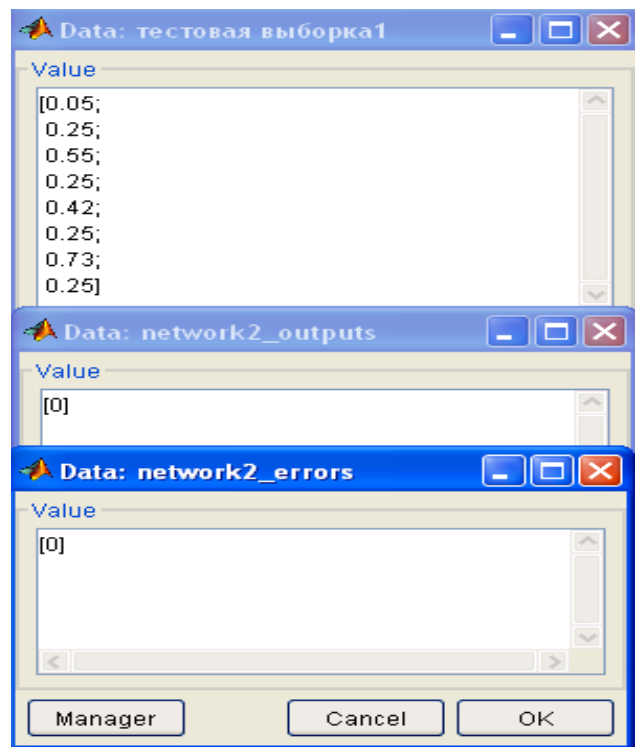

Figure 16. Neural network results for the bearing 6-180605

\section{CONCLUSIONS}

The most important prospects for the development of automated technology systems are intellectualization, increased reliability, and modular design. Diagnostics of technological systems increases their level of intellectualization and reliability. By analysing a method based on the analysis of methods of diagnostics of technological systems, it was concluded that the following diagnostic methods should be used for their diagnostics: by means of vibrations, temperature and electric current and by methods of Al. Analysis of the current state of algorithms and software products of automated diagnostic systems revealed a tendency to create diagnostic programs based on modular Al methods. Analysis of diagnostic equipment for technology systems has shown that the development of small diagnostic devices based on a microcontroller or processor for processing digital signals with excellent computational capabilities and a standard operating system for express-diagnostics that have a connection to an indepth diagnostics server, the trends in diagnostics are calculated: parameters, calculation of residual lifetime of MS, data archiving. Continuous diagnostic systems are recommended for diagnosing critical propulsion of technological systems in order to prevent accidents that can lead to human casualties, technological disasters or significant economic damage. It should be noted that diagnosis is dependent on the use of all types of sensors that are capable of measuring both electrical and non-electrical quantities.

1. On the spectrum of a bearing 6-180605 with a defect, the general vibration level increases by $0.7-0.8 \mathrm{~V}$ and wide peaks are observed at a frequency of $250 \mathrm{~Hz}$, which corresponds to the rolling frequency of the rolling bodies along the outer ring, and $340 \mathrm{~Hz}$, which corresponds to the rolling frequency of rolling bodies along the inner ring.

2. On the spectrum of bearing 6206 with a defect, an increase in the amplitude of vibrations is observed by $0.7-0.8 \mathrm{~V}$ at a frequency from $270 \mathrm{~Hz}$, which belongs to the frequency of rolling of rolling elements along the inner ring. The harmonics of the rotational speeds of the separator and the outer ring become noticeable.

3. In the presence of defects, the amplitude increases by an average of $0.75 \mathrm{~V}$ over the entire frequency spectrum, the vibration level increases by $1.5 \ldots 2 \mathrm{~V}$ at the frequencies of rotation of the rolling elements along the outer ring and the inner ring, with a radial load, the amplitude at the rotor 
speed increases and industrial frequency of $50 \mathrm{~Hz}$, and peaks appear at the speed of the separator.

4. The performed investigations show the possibility of application of artificial neural networks for detection of automated technological devices state according to diagnostic features. Neural networks and fuzzy logic are perspective mathematical apparatus for creation of systems of diagnosis of automated technological devices.

5. We got the results that both fuzzy logic and neural networks are suitable for diagnosing automatic devices. For the diagnosis of automatic devices with the help of neural networks, a certain set of data is required for serviceable and defective training devices. To diagnose automatic devices using fuzzy logic, it is necessary to draw up rules that determine the state of devices based on the values of the diagnostic parameters, their trends, taking into account the current operating mode and the exhausted resource.

6. The results can be used in practice to create smart automatic devices that will report on their technical condition, the presence of defects and predict the residual life of the work.

\section{ACKNOWLEDGMENTS}

The reported study was funded by RFBR according to the research project № 18-08-00772 A. and research project VEGA 1/0019/20.

\section{REFERENCES}

[Abramov 2015] Abramov I., Božek P., Nikitin Y.R., Abramov A., Sosnovich E., Stollmann V. Diagnostics of electrical drives. In: Proc. of Int. Conf. on Electrical Drivers and Power Electronics EDPE 2015. 21-23.09.2015, Tatranska Lomnica, The High Tatras, Slovakia, 2015; IEEE, New York, USA, pp. 364-367, ISBN 978-14673-9661-5.

[Abramov 2014a] Abramov I., Nikitin Y.R., Zorina O., Božek P., Stepanov P., Stollmann V. Monitoring of technical condition of motors and bearings of woodworking equipment. Acta Facultatis Xylologiae, 2014, Vol. 56 (2), pp. 97-104, ISSN 13363824.

[Abramov 2014b] Abramov I.V., Nikitin Y.R., Abramov A.I., Sosnovich E.V., Božek P. Control and diagnostic model of brushless DC motor. Journal of Electrical Engineering, 2014, Vol. 65, No. 5, pp. 277-282, ISSN 1335-3632.

[Aldrich 2013] Aldrich C., Auret L. Unsupervised Process Monitoring and Fault Diagnosis with Machine Learning Methods. Springer-Verlag London, 2013, p. 374, ISBN 97814471-5184-5.

[Basseville 1993] Basseville M., Nikiforov I.V. Detection of Abrupt Changes: Theory and Application. Prentice Hall information and system sciences series. Englewood Cliffs, New Jersey: Prentice Hall, 1993, p. 447.

[Calvo 2013] Calvo I., Pérez F., Etxeberria-Agiriano I., de Albéniz O.G. Designing High Performance Factory Automation Applications on Top of DDS. International Journal of Advanced Robotic Systems, 2013, Vol. 10, No. 4, 12 p.

[Cowan 2013] Cowan R.S., Winer W.O. Handbook of Technical Diagnostics: Fundamentals and Application to Structures and Systems. Machinery Diagnostics, Springer Berlin Heidelberg, 2013, pp. 387-410.

[Felkaoui 2017] Felkaoui A., Chaari F., Hadda M. Rotating Machinery and Signal Processing. In: Proc. 1st Workshop on Signal Processing Applied to Rotating Machinery Diagnostics, SIGPROMD'2017, April 09-11, 2017, Setif, Algeria; p. 131, ISSN 2363-698X.
[Frank 1990] Frank P.M. Fault diagnosis in dynamic systems using analytical and knowledge-based redundancy: a survey and some new results. Automatica, 1990, Vol. 26, Issue 3, pp. 459-474.

[Gots 1995] Gots I., Zajac J., Vojtko I. Equipment for measuring the degree of wear to cutting tools. Technisches messen, 1995, Vol. 62, No. 1, pp. 8-11.

[Guan 2015] Guan E., Fei J., Pan G., Fu Z., Yan W., Zhao Y. Fault Self-Diagnosis for Modular Robotic Systems Using M-Lattice Modules. International Journal of Advanced Robotic Systems, 2015, Vol. 12, No. 4, 11 p.

[Hammer 2010] Hammer M., Šimková M., Ministr M. Artificial Intelligence in Diagnostics of Electric Machines. Recent Advances in Mechatronics, Springer, Berlin Heidelberg, 2010, pp. 139-144.

[IME 2012] Institution of Mechanical Engineers. 10th International Conference on Vibrations in Rotating Machinery 11-13 September 2012. IMechE London, Oxford, Cambridge: Woodhead Publishing Limited, 2012, p. 776, ISBN 978-0-85709452-0.

[Isermann 2006] Isermann R. Fault-Diagnosis Systems: An Introduction from Fault Detection to Fault Tolerance. Springer, 2006, p. 475.

[Janglova 2004] Janglová D. Neural Networks in Mobile Robot Motion. International Journal of Advanced Robotic Systems, 2004, Vol. 1, Issue 1, pp. 15-22.

[Lee 2007] Lee Y.S., Kim Y.W. Condition monitoring of induction motors for vertical pumps with the current and vibration signature analysis. Experimental analysis of nano and engineering materials and structures, Springer, Dordrecht, 2007, pp. 419-420.

[Luo 2017] Luo H. Plug-and-Play Monitoring and Performance Optimization for Industrial Automation Processes. Springer Fachmedien Wiesbaden $\mathrm{GmbH}, 2017$, p. 158.

[Mohd 2013] Mohd Ashraf Ahmad, Mohd Zaidi Mohd Tumari, Ahmad Nor Kasruddin Nasir. Composite Fuzzy Logic Control Approach to a Flexible Joint Manipulator. International Journal of Advanced Robotic Systems, 2013, Vol. 10, Issue 1, 9 p.

[Nemeth 2017] Nemeth M., Michalconok, G., Peterkova A. The analysis of emerging failures of process control systems based on data mining. In: 21st IEEE Int. Conf. on Intelligent Engineering Systems (INES) ; Larnaca, Cyprus ; Oct. 20-23, 2017. Book Series: IEEE International Conference on Intelligent Engineering Systems, 2017, pp 55-60.

[Nemeth 2019] Nemeth M., Nemethova A., Michalconok G. Determination Issues of Data Mining Process of Failures in the Production Systems. In: 8th Computer Science On-Line Conference (CSOC). Czech Republic ; April 24-27, 2019. Artificial Intelligence Methods in Intelligent Algorithms. Book Series: Advances in Intelligent Systems and Computing, 2019, Vol. 985, pp. 200-207.

[Nikitin 2010] Nikitin Y.R., Abramov I.V. CNC machines diagnostics. In: Proceedings 13-th International Symposium on Mechatronics ; 2-4 June, 2010 ; Trencianske Teplice, Slovakia. ISBN 978-80-8075-451-8, DOI: 10.13140/2.1.2521.1204

[Peterkova 2017] Peterkova A., Michalconok G., Bohm A. Overview and Camparison of Machine Learning Methods to Build Classification Model for Prediction of Categorical Outcome Based on Medical Data. In: Conference on Computational Methods in Systems and Software (CoMeSySo); Vsetin, Czech Republic, Sept. 12-14, 2017. Book Series: Advances in Intelligent Systems and Computing, 2018, Vol. 661, pp 216-224.

[Peterkova 2018] Peterkova A., Nemeth M., Michalconok G., Bohm A. Computing importance Value of Medical Data Parameters in Classification Tasks and Its Evaluation Using 
Machine Learning Methods. In: 7th Computer Science On-Line Conference (CSOC). April, 2018. Book Series: Advances in Intelligent Systems and Computing, 2019, Vol. 763 pp. 397-405. [Pokorny 2012] Pokorny P., Peterka J., Vaclav S. The task of 5axis milling. Vol. 19, Issue 1, pp. 147-150.

[Rezoug 2012] Rezoug A., Hamerlain M., Hamerlain M., Tadjine M. Decentralized RBFNN Type-2 Fuzzy Sliding Mode Controller for Robot Manipulator Driven by Artificial Muscles. International Journal of Advanced Robotic Systems, 2012, Vol. 9 Issue 5, $12 \mathrm{p}$.

[Saitaev 2014] Saitaev D.V., Nikitin YR. Development of the device diagnostics of electric drives. In: Conference proceedings 4th Forum of Young Researchers. In the framework of International Forum “Education Quality - 2014"; April, 23, 2014, Izhevsk, Russia. Izhevsk: Publishing House of Kalashnikov ISTU, 2014, pp. 389-392, ISBN 978-5-7526-0649-6.

[Stepanov 2013] Stepanov P., Nikitin Y.R. Diagnostics of Mechatronic Systems on the Basis of Neural Networks with High-Performance Data Collection. In: Mechatronics 2013: Recent Technological and Scientific Advances; Oct. 7-9, 2013, Brno, Czech Republic. Springer Intrenational Publishing Swizerland, 2014, pp. 433-440. ISBN 978-3-319-02293-2.

[Stepanov 2014a] Stepanov P., Lagutkin S. Research of Electric and Mechanical Diagnostic Parameters of Drive Equipment. Applied Mechanics and Materials, 2014, vol. 683, pp. 177-281. [Stepanov 2014b] Stepanov P., Lagutkin S., Božek P., Nikitin Y.R. Comprehensive approach to technical conditions of electromechanical units in mechatronic systems. American
Journal of Mechanical Engineering, 2014, vol. 2, No. 7, pp. 278281.

[Tiwari 2018] Tiwari R. Rotor systems: analysis and identification. CRC Press, Taylor \& Francis Group, 2018. p. 1070, ISBN 9781138036284.

[Toro 2018] Toro G.F., Tsourdos A. UAV sensors for environmental monitoring. MDPI, 2018, $657 \mathrm{p}$.

[Trefilov 2019] Trefilov S.A., Nikitin Y.R. Robot drives diagnostics by identifiability criterion based on state matrix. In: Proceedings of the 5th International Forum Instrumentation Engineering, Electronics and Telecommunications 2019; Izhevsk, Russia; November 20-22, 2019. Izhevsk: Publishing House of Kalashnikov ISTU, 2019, pp. 123, pp 105-114, ISSN 2658-3658.

[Turygin 2018] Turygin Y., Božek P., Abramov I., Nikitin Y.R. Reliability Determination and Diagnostics of a Mechatronic System. Advances in Science and Technology, 2018, Vol. 12, No. 2, pp. 274-290. ISSN 2299-8624.

[Zhang 2010] Zhang W. Fault Detection. Intechopen, 2010, 504 p. ISBN 978-953-307-037-7.

[Zidek 2016] Zidek K., Maxim V., Pitel J., Hosovsky A. Embedded vision equipment of industrial robot for inline detection of product errors by clustering-classification algorithms. International Journal of Advanced Robotic Systems, 2016, Vol. 13 Issue 5, pp. 1-10.

\section{CONTACTS:}

Prof. Dr. Ing. Jozef Peterka

Slovak University of Technology in Bratislava,

Faculty of Materials Science and Technology in Trnava,

Ulica Jána Bottu č. 2781/25, 917 24, Trnava, Slovak Republik

Telephone: +421905930 245, e-mail: jozef.peterka@stuba.sk

Dr. Yury Rafailovich Nikitin

Kalashnikov Izhevsk State Technical University,

Mechatronic Systems" Department,

7, Studencheskaya str, Izhevsk, Russia, 426069

e-mail: nikitin@istu.ru

Dr.h.c. Prof. Ing. Pavol Bozek, CSc.

Slovak University of Technology in Bratislava,

Faculty of Materials Science and Technology in Trnava,

Ulica Jána Bottu č. 2781/25, 917 24, Trnava, Slovak Republik

e-mail: pavol.bozek@stuba.sk 